\title{
On the Endogenous Sustainability of Economic Growth: Why Is the Scale of Government Enlarged?
}

\author{
Masayuki Otaki \\ Institute of Social Science, University of Tokyo, Tokyo, Japan \\ Email: ohtaki@iss.u-tokyo.ac.jp
}

Received March 23, 2013; revised April 23, 2013; accepted May 23, 2013

Copyright (C) 2013 Masayuki Otaki. This is an open access article distributed under the Creative Commons Attribution License, which permits unrestricted use, distribution, and reproduction in any medium, provided the original work is properly cited.

\begin{abstract}
Almost every developed country experiences serious enlargement of the scale of government, specifically the expansion of fiscal deficits. We inquire why such a phenomenon is so prominent based on a Keynesian growth model entirely compatible with a standard neoclassical microeconomics. The cost-minimizing investment plays a key role. Whenever the demand that each firm faces is constrained by the effective demand (such case includes the situation of monopolistic competition), a firm strives to raise the productivity of labor and save its production cost. Such a process incessantly continues even if the effective demand is kept intact. It also implies that the unemployment would tend to be unbounded because the labor productivity improves under the constant effective demand. As such, a ceaseless expansionary aggregate demand policy is inevitably required for sustaining explosive potentials of production.
\end{abstract}

Keywords: Endogenous Sustainability of Economic Growth; Accumulation of Fiscal Deficits; Cost-Reduction Investment; Principle of Effective Demand

\section{Introduction}

Almost every developed economy is bothered by the huge amount of fiscal deficit and/or accumulation of public debts. Where do such, at least seemingly, serious economic difficulties stem from? The article approaches this political economic issue by applying a new type of a Keynesian economic-growth theory which is completely consistent with standard neoclassical microeconomics postulates.

The crucial factor is the potential excess production capacity that is delivered by the labor-productivity enhancing, thereby, cost reduction investment. Whenever each employer faces his downward sloping demand curve the location of which is determined by the effective demand in monopolistic competition, it implies that his business opportunity is ultimately limited by the effective demand economy as a whole. Thus, it is urgently necessary for each employer to improve the labor productivity via effective wage-cost reduction. Since such an economic motive ceaselessly works independent of the level of effective demand, even if it is not a conscious consequence, it enlarges the potential production capacity economy as whole relatively to the effective demand. It immediately cases the serious unemployment problem unless some legitimate aggregate-demand management policies are adopted.

For expanding the effective demand that matches the explosive aggregate production potential, the enlargement of fiscal expenditure with non-negligible budget deficit is unavoidable. That is, the role of government is forced to be more active to secure stable jobs evenly to employees who are threatened by the mass unemployment under the incessant labor-productivity growth. Succinctly, economic growth in the monetary market economy is unsustainable per se, and it becomes to heavily rely on the governmental economic activities.

It is also noteworthy that Buchanan and Wagner [1], although it is a superficial and journalistic book, criticized that Keynes and his successors, including voters, underestimate the true social cost of fiscal expenditure, and such tendency exacerbates budget deficits. However, according to our view, the enlargement of government is inevitable owing to generic properties of the monetary market economy, not to the irrational recognitions and/or greedy political rent seeking.

In the standard neoclassical economic-growth theory (e.g. Solow [2], Swan [3], Romer [4]), such a tragedy never occurs. This is because there never exists the concept of effective demand in the theory. Incomes are de- 
termined by the amount of existing production resources, and all savings are automatically absorbed by the capital investment independent of income level. However, as developed by Otaki $[5,6]$, these optimistic properties of the model never preserved in the monetary economy where money possesses its intrinsic value.

The reason why money circulates beyond generations is the faith to its intrinsic value. That is, the function of the monetary economy decisively depends on the people's belief that the future purchasing power of money kept stable. Since the future price level (the inverse of the purchasing power of money) affects the current price via current wage-price setting, the faith to the intrinsic value of money quite naturally leads us to endogenous current price inflexibility.

As such, it is a rather rare case in which the full-employment equilibrium is attained within a monetary economy. Unless ample money is provided via fiscal-monetary policy, the principle of effective demand works and incomes and savings are subject to the volume of the capital investment. To summarize, our growth theory deals with the economic phenomena in a monetary economy, and the scope of the neoclassical growth-theory is limited to a barter economy.

The article consists of the rest three sections. In Section 2, using a standard overlapping generations model in production economy, we construct a Keynesian growth model with money and tangible/intangible assets improving the labor productivity. Section 3 deals with some comparative statics and induces some important policy implications. Section 4 provides brief concluding remarks.

\section{The Model}

\subsection{Structure of the Model}

The deployed model basically depends on Otaki [7]. We consider a two period overlapping-generations model with infinite time horizon. In our economy, there are two social strata; employers and employees. Each employer consists of a kind of dynasty and specializes in producing some differentiated good $z$. He maximizes his own lifetime utility comparing with benefits of his descendants that are delivered by the accumulation of tangible/intangible assets that promote the labor productivity $\gamma_{t}{ }^{1}$. His income is the profits of his firm when he is young.

An employee also maximizes his lifetime utility. He can provide unit labor only when he is young and prepares for his retirement by hoarding money. We assume that the disutility of labor is $\beta$.

There are three kinds of market in this economy: the goods markets, labor markets, and money market. By Walras' law, we can skip the equilibrium condition for the money market. In addition, we assume that the real government expenditure is not enough, and imperfect employment equilibrium prevails. And thus, labor market is in equilibrium when the real reservation wage, which will be defined below, is equalized to the disutility of labor.

Goods are differentiated within the interval $Z \equiv[0,1]$. The lifetime utility function from consumption is identical between strata and is defined as

$$
\begin{aligned}
& U_{t} \equiv\left[c_{1 t}\right]^{1-s}\left[c_{2 t+1}\right]^{s}, c_{i t} \equiv\left[\int_{0}^{1}\left[c_{i t}(z)\right]^{1-\eta^{-1}} \mathrm{~d} z\right]^{\frac{1}{1-\eta^{-1}}}, \\
& 0<s<1, \eta>1
\end{aligned}
$$

where $c_{i t}$ is the aggregate consumption level of an individual who belongs to the ith generation during period $t^{2}$.

The demand function $D_{t}(z)$ for good $z \in Z$ becomes

$$
D_{t}(z)=\left[\frac{p_{t}(z)}{P_{t}}\right]^{-\eta} y_{t}, P_{t} \equiv\left[\int_{0}^{1}\left[p_{t}(z)\right]^{1-\eta} \mathrm{d} z\right]^{\frac{1}{1-\eta}}
$$

where $p_{t}(z)$ denotes the price of good $z$ during period $t$, and $P_{t}$ is the price index derived from instantaneous utility maximization. $y_{t}$ is the real effective demand deflated by $P_{t}$. Furthermore, since the lifetime utility function is the Cobb-Douglas type, the aggregate saving function $S_{t}$ becomes

$$
S_{t}=s y_{t}
$$

All above discussions are concerning common properties across strata. Next, we shall depict the peculiar decision process of each stratum.

\subsection{Employees}

An employee faces the decision problem whether he participates or not. As above discussed, in any imperfect employment equilibrium, the real reservation wage is equalized to the disutility of labor, and thus any employee is indifferent whether to work or not. Since the indirect lifetime utility $I U_{t}$ derived from consumption is expressed by

$$
I U_{t}=\frac{W_{t}}{A\left[P_{t}\right]^{1-s}\left[P_{t+1}\right]^{s}}, A \equiv s^{s}[1-s]^{1-s}
$$

\footnotetext{
${ }^{1}$ This assumption is based on impure altruism (Acemoglu [8]). See, for example, Andreoni [9], Banerjee and Newman [10,11], Galor and Zeira [12] and Aghion and Bolton [13], concerning the neoclassical model based on impure altruism. However, the policy implications are entirely different between preceding research and this article.

${ }^{2}$ The Cobb-Douglas form of the lifetime utility function is deployed mainly because of excluding the effect of inflation to consumption/ saving decision that seems not only less important for analyzing a long-run economic problem such as economic growth but also consistent with empirical analyses.
} 
the nominal reservation wage $W_{t}^{R}$ satisfies the following equation:

$$
\frac{W_{t}^{R}}{A\left[P_{t}\right]^{1-s}\left[P_{t+1}\right]^{s}}=\beta \Rightarrow W_{t}^{R}=A\left[P_{t}\right]^{1-s}\left[P_{t+1}\right]^{s} \beta .
$$

\subsection{Employers}

We assume that the gain obtained from the progress of the labor productivity is equivalent to the same amount of future consumption, although the former is attributed to the next generation. In addition, savings per an employer are so abundant that there is no necessity of external borrowing.

Under these two assumptions, we can separate employer's saving decision from that for the capital investment because there is not substantive difference between money hoarding and capital investment. An employer's decision becomes 1 ) he decides how much he should save for maximizing the lifetime utility; 2) given the optimal saving, he should decide how much savings are alloted to the capital investment.

We have already solved the first-step optimization problem that is expressed in (3). Since, by assumption, the second-step optimization does not affect the first-step problem, what is left for us is to solve the optimal capital investment decision. The problem is formatted as

$$
\max _{\gamma_{t}}\left[-P_{t}\left[\frac{\gamma_{t}}{\gamma_{t-1}}\right]^{\alpha}-\frac{1}{1+\tau} \frac{W^{R}\left(P_{t+1}, P_{t+2}\right) y_{t+1}}{\gamma_{t}}\right],
$$

where $\left[\frac{\gamma_{t}}{\gamma_{t-1}}\right]^{\alpha}$ is the adjustment cost function for the capital investment. $\tau$ denotes the heritage tax rate incurred on the gain from the cost-reduction capital investment. We assume that the tax rate is proportionate to the inflation rate, and thus $\tau=\frac{p_{t+1}}{p_{t}}-1$ holds. The first term of (6) is the cost of capital investment which enhances the labor productivity $\gamma$. The second term denotes the total wage cost which will be economized by the capital investment.

From the linear homogeneity of $W^{R}(\cdot)$,

$$
W^{R}\left(P_{t+1}, P_{t+2}\right)=P_{t+1} W^{R}\left(1, \frac{P_{t+2}}{P_{t+1}}\right) .
$$

Substituting (7) into (6), (6) is transformed into

$$
\max _{\gamma_{t}}\left[-\left[\frac{\gamma_{t}}{\gamma_{t-1}}\right]^{\alpha}-\frac{W^{R}\left(1, \frac{P_{t+2}}{P_{t+1}}\right) y_{t+1}}{\gamma_{t}}\right],
$$

The first-order condition for (8) is

$$
\alpha\left[\frac{\gamma_{t}}{\gamma_{t-1}}\right]^{\alpha}=\frac{W^{R}\left(1, \frac{P_{t+2}}{P_{t+1}}\right) y_{t+1}}{\gamma_{t}} .
$$

The profit-maximization condition requires

$$
p_{t+1}(z)=\frac{W^{R}\left(P_{t+1}, P_{t+2}\right)}{\gamma_{t}\left[1-\eta^{-1}\right]} \Rightarrow 1-\eta^{-1}=\frac{W^{R}\left(1, \frac{P_{t+2}}{P_{t+1}}\right)}{\gamma_{t}} .
$$

Combining (9) and (10), finally we obtain the investment cost function as

$$
\left[\frac{\gamma_{t}}{\gamma_{t-1}}\right]^{\alpha}=\frac{1-\eta^{-1}}{\alpha} y_{t+1}
$$

\subsection{The Government}

The government issues fiat money to finance its real expenditure $g_{t}$. For simplicity, such expenditure is entirely wasteful and contributes to neither individual's utility nor the progress of the labor productivity. The budget constraint can be written as

$$
m_{t}=[1+\theta] m_{t-1}, g_{t}=\theta m_{t-1}+\left[1-\frac{P_{t-1}}{P_{t}}\right] m_{t-1}
$$

where $m_{t}$ is the real cash balance during period $t$, which is defined by $m_{t} \equiv \frac{M_{t}}{P_{t}}$. The first term of the right-hand side of (12) is the newly issued money that is equal to the budget deficit. The second term represents the seignorage of money obtained via inflation.

\subsection{Equilibrium Condition for Aggregate Goods Market}

From (3), (11) and (12), the equilibrium condition for the aggregate goods market is

$$
\begin{aligned}
s y_{t} & =\frac{1-\eta^{-1}}{\alpha} y_{t+1}+g_{t}+\frac{P_{t-1}}{P_{t}} m_{t-1} \\
& =\frac{1-\eta^{-1}}{\alpha} y_{t+1}+[1+\theta] m_{t-1}
\end{aligned}
$$

where the third term of the right-hand side of (13) is the aggregate consumption of old generation. Solving (13) on $y_{t}$, we obtain the equilibrium GDP as

$$
y_{t}^{*}=\frac{1+\theta}{1-\frac{1-\eta^{-1}}{\alpha s}} \frac{m_{t-1}}{s} .
$$

Using (12) and (14), the equilibrium economic growth 
rate becomes

$$
\frac{y_{t+1}^{*}}{y_{t}^{*}}=1+\theta .
$$

Thus, we obtain the following theorem.

Theorem 1. The monetary market economy cannot attain economic growth without fiscal deficits.

\section{Proof.}

It is clear from setting $\theta=0$ in (15).

\section{The Sustainability of Economic Growth and Fiscal Deficits}

In this section, we discuss the sustainability of economic growth in our monetary market economy. To begin with, we shall define the sustainability.

Definition 1. We call economic growth is sustainable only when it never reduces the level of employment.

Although unemployment is voluntary in this model, it is not difficult to turn it involuntary if we use the method developed by Otaki [6]. Hence, at least for employees, economic growth is harmful unless the economy is sustainable.

Since the equilibrium employment level $L_{t}^{*}$ satisfies $L_{t}^{*} \equiv \frac{y_{t}^{*}}{\gamma_{t-1}^{*}}$, whether or not economic growth in our monetary market economy is sustainable can be judged from the following inequality.

$$
\Delta L \equiv \frac{\frac{y_{t+1}}{y_{t}}}{\frac{\gamma_{t}}{\gamma_{t-1}}}>1 .
$$

When above inequality holds, economic growth is sustainable, otherwise unsustainable.

From (15), $\frac{y_{t+1}}{y_{t}}=1+\theta$. Solving (11) on $\frac{\gamma_{t}}{\gamma_{t-1}}$, we obtain

$$
\frac{\gamma_{t}}{\gamma_{t-1}}=\sqrt[\alpha]{\frac{1-\eta^{-1}}{\alpha} y_{t+1}} .
$$

Accordingly, (16) becomes

$$
\Delta L=\frac{1+\theta}{\alpha \sqrt{\frac{1-\eta^{-1}}{\alpha} y_{t+1}}} .
$$

Since $y_{t+1}$ grows at the velocity $1+\theta, \Delta L$ eventually decreases on sufficient large $t$ for any given $\theta$. Such a property of our monetary market economy is summarized by the following theorem, that is,

Theorem 2. Economic growth in the monetary market economy is unsustainable at least in the long run. Even if expansionary fiscal policy that is financed by budget deficit can temporarily stimulate the economy and boosts the employment in the short run, it will be surpassed by the cost-reduction behavior of capital accumulation and the growth ultimately becomes unsustainable in the long run.

This dismal theory explains why the scale of a government is enlarged. Since the improvement of employment brought about by some fiscal expansion become ineffective with the advance of labor-productivity enhancing capital accumulation, more stimulative and more expensive policies are required for sustaining employment level. Such policies inevitably accumulate huge fiscal deficits, and thus the scale of government is enlarged.

\section{Concluding Remarks}

In this article, we have analyzed the properties of economic growth in a monetary market economy by a Keynesian growth model with a rigorous neoclassical microeconomic foundation. The obtained results are as follows.

First, although capital investment stimulates the effective demand, such an expansionary effect is not strong enough to promote economic growth. Hence, the monetary market economy cannot grow without some exogenous stimuli such as fiscal policies. However, such policies possibly incurs non-negligible fiscal deficits.

Second, since the labor productivity steadily grows by the capital investment even if the economy records no growth, it provokes the serious unemployment problem. To dissolve such a difficulty, artificial growth promoting policies seem to be desirable. However, not only these policies enlarge budget deficits but also the accelerated growth rate will be exceeded by the progress of the labor productivity, at least, in the long run, thereby emerging the unemployment problem once again. In this sense, expansionary fiscal policy is not an ultimate cure for the problem, and thus economic growth in the monetary market economy is not sustainable.

\section{REFERENCES}

[1] J. M. Buchanan and R. E. Wagner, "Democracy in Deficit: The Political Legacy of Lord Keynes,” Reprinted by Liberty Fund, INC., Indianapolis, 1977.

[2] R. M. Solow, "A Contribution to the Theory of Economic Growth,” Quarterly Journal of Economics, Vol. 70, No. 1, 1956, pp. 65-94. doi:10.2307/1884513

[3] T. W. Swan, "Economic Growth and Capital Accumulation,” Economic Record, Vol. 32, No. 2, 1956, pp. 334361. doi:10.1111/j.1475-4932.1956.tb00434.x

[4] P. M. Romer, "Increasing Returns and Long-Run Growth," Journal of Political Economy, Vol. 94, No. 5, 1986, pp. 1002-1037. doi:10.1086/261420

[5] M. Otaki, “The Dynamically Extended Keynesian Cross 
and the Welfare-Improving Fiscal Policy,” Economics Letters, Vol. 96, No. 1, 2007, pp. 23-29.

doi:10.1016/j.econlet.2006.12.005

[6] M. Otaki, “A Welfare Economics Foundation for the FullEmployment Policy,” Economics Letters, Vol. 102, No. 1, 2009, pp. 1-3. doi:10.1016/j.econlet.2008.08.003

[7] M. Otaki, "A Keynesian Endogenous Growth Theory with a Rigorous Microeconomic Foundation,” Theoretical Economics Letters, Vol. 2, No. 4, 2012, pp. 369-372. doi:10.4236/tel.2012.24067

[8] D. Acemoglu, "Introduction to Modern Economic Growth," Princeton University Press, Princeton, 2009.

[9] J. Andreoni, "Giving with Impure Altruism: Applications to Charity and Ricardian Equivalence,” Journal of Political Economy, Vol. 97, No. 6, 1989, pp. 1447-1458. doi:10.1086/261662

[10] A. V. Banerjee and A. Newman, "Risk Bearing and the Theory of Income Distribution,” Review of Economic Studies, Vol. 58, No. 2, 1991, pp. 211-235. doi: $10.2307 / 2297965$

[11] A. V. Banerjee and A. Newman, "Occupational Choice and the Process of Development," Journal of Political Economy, Vol. 101, No. 2, 1993, pp. 274-298. doi:10.1086/261876

[12] O. Galor and J. Zeira, "Income Distribution and Macroeconomics," Review of Economic Studies, Vol. 60, No. 1, 1993, pp. 35-52. doi:10.2307/2297811

[13] P. Aghion and P. Bolton, "A Theory of Trickle-Down Growth and Development," Review of Economic Studies, Vol. 64, No. 2, 1997, pp. 151-172. doi:10.2307/2971707 